\title{
Life events, psychiatric illness and the irritable bowel syndrome
}

\author{
M J FORD, P McC MILLER, JENNY EASTWOOD, AND M A EASTWOOD \\ From the Gastrointestinal Unit, Western General Hospital, Edinburgh, and the MRC Unit for Epidemiological \\ Studies in Psychiatry, Royal Edinburgh Hospital, Edinburgh.
}

SUMmaRY The frequency, severity, and characteristics of psychiatric illness and stressful life situations were assessed in 134 patients aged 18-60 years referred to a gastrointestinal clinic by their general practitioner. A functional disorder of the gastrointestinal tract was established in $72 \%$. A formal psychiatric assessment in 64 randomly selected patients revealed a previous or current psychiatric disorder in $54 \%$ of the functional group and $12.5 \%$ of the organic group. Stressful life events before referral were assessed by a modification of the Bedford College methodology. Anxiety provoking life situations were found in $30 \%$, a proportion which was not significantly different in the two groups. Psychiatric illness episodes and/or anxiety provoking situations, preceded the onset of bowel symptoms in two-thirds of the functional group, however, but in none of the organic group. Life situations alone did not appear to be associated with functional disorders unless they provoked an anxiety state.

Functional disorders of the gastrointestinal tract are the most common of all gastrointestinal disorders and account for $50 \%$ of referrals to a gastrointestinal clinic. 'The majority of such patients have an irritable bowel syndrome characterised by abdominal pain associated with a change in bowel habit in the absence of demonstrable organic disease. In a randomly selected normal population, one-third regularly experienced similar gastrointestinal symptoms two-thirds of whom admitted to abdominal pain associated with a change in bowel habit. ${ }^{2}$ Despite the frequency of gastrointestinal symptoms in an apparently healthy population, less than a quarter consult their general practitioner because of these symptoms. ${ }^{2}$ If these symptoms are widely prevalent yet do not precipitate requests for consultation, the implication is that patients seeking advice do so either because the severity of symptoms is greater or there is a reduced tolerance due to other factors - for example, psychiatric illness or psychosocial distress. ${ }^{34}$

This study was undertaken to assess the frequency, severity and characteristics of psychiatric illness and stressful life situations in patients referred to a

\footnotetext{
Address for correspondence: Dr M J Ford, Consultant Physician, Medical Unit, Leith Hospital, Edinburgh, EH6 6TH

Received for publication 30 May 1985
}

gastrointestinal clinic by their general practitioners. An analysis of the timing and inter-relationship of illness onset, stressful life situations and psychiatric illness episodes was undertaken to identify a possible pathogenetic mechanism in functional gastrointestinal disorders.

\section{Methods}

\section{PATIENTS}

During a 12 week period, outpatients, aged between 18 and 60 years living within the Edinburgh city boundaries and referred by general practitioners to a gastrointestinal clinic, were invited to participate in the study. At least $75 \%$ of the general practitioner referrals to each of three consultant gastroenterologists were to be recruited without biased selection. Patients were to be intercepted by one of us (MJF) as they left the consulting rooms and with their informed consent, details of age, sex, marital and occupational status were recorded. The precise duration of the presenting symptoms was established and using a questionnaire, an inventory was obtained of the nature and frequency of occurrence of symptoms characterising gastrointestinal disorder. ${ }^{56}$

In order to ensure that patients to be interviewed at home were representative of all referrals, alternate patients were then invited to cooperate in the study. 
This identified at least six patients each week who could be interviewed in detail. Only patients who could be interviewed within three months of the date of the general practitioner's referral letter were included in the study so that the psychiatric and life situation data recorded spanned a minimum of three months before hospital referral. The domiciliary interviews were undertaken by trained and experienced interviewers. The interviewers, who were blind to the clinical diagnosis, recorded details of the nature and timing of any life events and difficulties occurring during the preceding six months. A formal structured psychiatric assessment spanning the same time period was tape recorded.

The psychiatric assessment used was a modification of the Present State Examination designed to identify psychiatric symptoms experienced during the six months before interview. ${ }^{7}$ Details of the time of onset and remission of psychiatric symptoms were recorded on tape and later assessed independently by one of us (JE). The index of definition criteria (IDC) and the research diagnostic criteria (RDC) were then applied to determine whether the patient constituted a psychiatric 'case' at interview and/or during the six months before interview. ${ }^{8}$ For those patients who were 'cases' the date of onset of the earliest episode was defined.

The life situation data were recorded using a modification of the Bedford College Life Events and Difficulties Schedule (LEDS). ${ }^{9}$ The patient was shown a list of commonly encountered life situations and then carefully questioned about those which had occurred and involved them or people close to them during the six months before interview. The Bedford system classifies a life situation as an 'event' when it is an occurrence with a precise timing - for example, death, or as a 'long term difficulty' when the occurrence is extended in time - for example, a financial problem. In the modified version, the nature of each event or difficulty is then further defined by a contextual rating method using six dimensions. ${ }^{9}$ These dimensions were labelled threat $(\mathrm{T})$, personal loss $(\mathrm{L})$, choice of action $(\mathrm{C})$, uncertainty of outcome (U), hopeless situation (H) and antisocial act (A). Each of the six characteristics was rated as present or absent; thus the death of a parent might be described as $\mathrm{L} \mathrm{H}$ (loss and hopelessness) while an assault on a policeman might be C U A T (choice of action over whether to plead guilty, uncertainty of outcome of court case, antisocial act and threat). There is good evidence that stressful situations for anxiety differ significantly from those for depression. ${ }^{10}$ Previous research has identified and quantified which of the 64 possible combinations are more likely to be associated with anxiety disorders alone or in combination with depression. ${ }^{11}$ In practice, 13 combinations of this type are most often encountered and all were observed in the present study (CHAT, CUHT, CHT, CAT, CUT, UHT, CUA, LH, CH, CL, UH, UA, CA). Such anxiety provoking situations were analysed by a simple numerical count. In addition, in view of the known differences between certain life situations in their ability to provoke anxiety and to assess the sensitivity of the analytical methods, a weighting system was also used. Using previous work, weights were assigned to each of these combinations and then summed for all the events and difficulties over the six month period. CHAT, CUHT, CHT, LH - each scored 4, CAT, CUT, UHT, CH, CL - each scored 2, and CUA, UH, UA, CA - each scored 1 . The dates of onset of long term difficulties were noted and when the difficulty had been present for longer than six months, it was scored both as it had been experienced during the previous six months and as it would have scored had it been assessed at time of onset.

A single final diagnosis, considered by one of us (MJF) to be the principal cause of gastrointestinal symptoms precipitating referral, was recorded for each patient. This diagnosis was based upon the consultant's working diagnosis after completion of the investigations considered necessary to establish the principal diagnosis. Details of the formal psychiatric assessment were not available either to the consulting doctor or to the person reviewing the case records. The retrospective analysis of the medical case records was undertaken not less than 12 weeks after the initial consultation to allow sufficient time to elapse so that the presence or absence of organic disease could be firmly established. Patients were allotted to one of four groups: upper abdominal/lower abdominal/functional/organic to facilitate subsequent analysis. The MRC Unit for Epidemiological Studies in Psychiatry had previously undertaken studies on a random sample of women not seeking health care using the electoral register. ${ }^{78}$ Potential controls who had suffered from gastrointestinal disorders were excluded. Using these normal subjects, a match was found for each woman in the functional group. Patients were matched with controls by age, marital status and social class and when more than one possible match was available, the choice was random. No control could be found to match the one young widow in the group.

\section{Results}

During the 12 week period of the study, 244 new outpatients were referred by their general practitioner. One hundred and fifty nine patients $(65 \%)$ were aged between 18 and 60 years of whom 139 $(87 \%)$ were approached, the remainder having left 
the clinic before an approach could be made; 134 agreed to cooperate in the study and five declined. Eighty patients $(50 \%$ of the original 159 patients) were invited to participate in the detailed domiciliary interview and 64 patients were interviewed within three months of the date of the referral letter. Of the 16 patients not interviewed, eight declined, the consent of the general practitioner was unavailable in two and in six, the interview could not be arranged within 12 weeks from the date of referral.

Details of the 134 patients aged between 18 and 60 years who were referred by their general practitioner are shown in Table 1. No significant differences were found between the functional and organic groups with respect to age, sex, marital status, and social class using Student's $t$, Wilcoxon's rank sum and $\chi^{2}$ tests as appropriate. After appropriate investigation, no evidence of organic disease was found in $97(72 \%)$ three months after the initial clinic consultation. This functional group comprised $65 \%$ of the male referrals and $78 \%$ of the female referrals. Male patients were significantly older than female patients; the mean age of the men was 41 years and women 35 years $(t=2 \cdot 8$, $\mathrm{p}<0 \cdot 01)$. The functional group comprised the irritable bowel syndrome $(75 \%)$ and functional dyspepsia $(23 \%)$. The organic group largely comprised peptic ulceration $(57 \%)$ and inflammatory bowel disease $(16 \%)$.

Psychiatric and life situation interviews were undertaken in 64 patients of whom 48 (31 women) had a functional disorder and 16 (eight women) an organic disorder. Using RCD and ID criteria, current psychiatric 'caseness' was established in 20 of the 48 patients with a functional disorder $(42 \%)$ compared with only one of 16 patients with an organic disorder $(6 \%)$. ( $\chi^{2}$ with Yates' correction $\left.=5 \cdot 3, p<0 \cdot 025\right)$ (Table 2). The psychiatric disorders comprised anxiety states, a third of which were present in

Table 1 General practitioners GI referrals (aged 18-60 years)

\begin{tabular}{lll}
\hline & $\begin{array}{l}\text { Functional disorder } \\
(n=97)\end{array}$ & $\begin{array}{l}\text { Organic disorder } \\
(n=37)\end{array}$ \\
\hline Paticnts (\%) & 72 & 28 \\
Mean age (SE) years & $37 \cdot 0(1 \cdot 4)$ & $38 \cdot 7(2 \cdot 7)$ \\
Sex ratio (M:F) & $35: 62$ & $19: 18$ \\
Marital status: & & \\
Single & 23 & 6 \\
Married & 64 & 26 \\
Divorced/separated & 7 & 5 \\
Widowed & 3 & 0 \\
Social class: & & \\
I & 6 & 6 \\
II & 23 & 7 \\
III & 40 & 10 \\
IV & 22 & 10 \\
V & 6 & 4 \\
\hline
\end{tabular}

Table 2 Current psychiatric disorder, anxiety provoking life situations and GI disorders

\begin{tabular}{llll}
\hline $\begin{array}{l}\text { Psychiatric } \\
\text { caseness' }\end{array}$ & $\begin{array}{l}\text { Anxiety provoking } \\
\text { life situation }\end{array}$ & $\begin{array}{l}\text { Functional } \\
\text { disorder } \\
(n=48)\end{array}$ & $\begin{array}{l}\text { Organic } \\
\text { disorder } \\
(n=16)\end{array}$ \\
\hline $\begin{array}{c}\text { Cases' } \\
(n=21)\end{array}$ & $\begin{array}{l}\text { Present } \\
\text { Absent }\end{array}$ & 9 & 0 \\
$\begin{array}{c}\text { Non-cases' } \\
(n=43)\end{array}$ & $\begin{array}{l}\text { Present } \\
\text { Absent }\end{array}$ & 6 & 1 \\
\hline
\end{tabular}

Significance: Psychiatric 'caseness' (F v O) $\chi^{2}$ (Yates) $=5 \cdot 3, \mathrm{p}<0.025$ Anxiety provoking life situation ( $\mathrm{FvO}$ ) NS

combination with depression. Anxiety provoking situations were present in $15(31 \%)$ of patients with functional disorders compared with four $(25 \%)$ of patients with organic disorders, a difference which was not statistically significant. Weighting the anxiety provoking situations also failed to differentiate the two groups; the mean score in the functional group was 1.6 and in the organic group, $0.8(t=0.9)$ (Table 2).

In an attempt to show a possible causal relationship, psychiatric episodes and anxiety provoking situations were assessed in relation to the time of onset of the bowel disorder (Table 3). Some of the patients had suffered bowel symptoms for several years and although the psychiatric and life situation data were based on the six months before interview, many of the psychiatric illness episodes and life situations had also lasted several years and had preceded the onset of bowel symptoms. Some psychiatric illness episodes and life situations which had occurred before the six month period will inevitably have been overlooked but this possibility would if anything minimise possible differences between the functional and organic groups. Accepting these limitations and that the numbers are small, 15 (31\%) of the 48 patients with functional disorders had experienced psychiatric illness before the onset of

Table 3 Anxiety provoking life situations and psychiatric disorder before the onset of bowel disorder

\begin{tabular}{llll}
\hline & $\begin{array}{l}\text { Functional } \\
\text { disorder } \\
(n=48)\end{array}$ & $\begin{array}{l}\text { Organic } \\
\text { disorder } \\
(n=16)\end{array}$ & $\begin{array}{l}\text { Significance } \\
\left(\chi^{2}\right) \text { Yates' }\end{array}$ \\
\hline $\begin{array}{c}\text { Psychiatric episode present } \\
\text { before bowel disorder } \\
(n=15)\end{array}$ & 15 & 0 & $\begin{array}{l}4 \cdot 9 \\
\mathrm{p}<0 \cdot 05\end{array}$ \\
$\begin{array}{c}\text { Anxiety provoking situation } \\
\text { present before bowel } \\
\text { disorder (n=19) }\end{array}$ & 17 & 2 & $2 \cdot 0$ \\
$\begin{array}{c}\text { Psychiatric episode and/or } \\
\text { anxiety provoking situation } \\
\text { present before bowel } \\
\text { disorder (n=35) }\end{array}$ & 31 & 4 & $\begin{array}{l}\mathbf{p}<0 \cdot 20 \\
\mathrm{p}<0 \cdot 02\end{array}$ \\
\hline
\end{tabular}


Table 4 Anxiety provoking situations and psychiatric disorder in women with functional disorders and matched controls

\begin{tabular}{llll}
\hline & $\begin{array}{l}\text { Functional } \\
\text { disorder } \\
(n=30)\end{array}$ & $\begin{array}{l}\text { Healthy } \\
\text { controls } \\
(n=30)\end{array}$ & $\begin{array}{l}\text { Significance } \\
\left(\chi^{2}\right)\end{array}$ \\
\hline Current psychiatric 'caseness' & 12 & 5 & $\begin{array}{l}4 \cdot 0 \\
\mathrm{p}<0 \cdot 05\end{array}$ \\
$\begin{array}{l}\text { Anxiety provoking situation(s) } \\
\text { present }\end{array}$ & 6 & 8 & NS \\
\hline
\end{tabular}

bowel symptoms whereas none of the patients with organic disorders had done so, a difference which was statistically significant. ( $\chi^{2}$ with Yates' correction $=4.9, \mathrm{p}<0.05)($ Table 3$)$. No significant differences were found between the groups with respect to the presence or absence of an anxiety provoking situation. There was, however, a highly significant difference in the occurrence of either psychiatric illness episodes or anxiety provoking situations before the onset of bowel symptoms. ( $\chi^{2}$ with Yates' correction $=6 \cdot 1, \mathrm{p}<0 \cdot 02$ ).

A comparison of the 30 women with a functional disorder with matched controls is shown in Table 4. Psychiatric 'caseness' was significantly more common in the functional group; $40 \%$ had a current psychiatric disorder compared with $17 \%$ of controls $\left(\chi^{2}=4 \cdot 0\right.$, $p<0.05)$. With the exception of one patient in the control group, depressive disorders did not occur except in combination with an anxiety state. At least one anxiety provoking situation was experienced by $23 \%$ of the 60 patients and controls, a proportion which did not differ significantly between the groups.

\section{Discussion}

Functional disorders of the alimentary tract account for up to $50 \%$ of all referrals to a gastrointestinal clinic. ${ }^{12}$ As $45 \%$ of the 244 original referrals were specifically excluded from the present study because of the age limits, the overall proportion of our patients with a functional disorder $(40 \%)$ is comparable with that previously reported. ${ }^{13} \mathrm{We}$ have shown that $72 \%$ of patients aged between 18 and 60 years had a functional gastrointestinal disorder of whom three quarters had an irritable bowel syndrome and a quarter, functional dyspepsia. It could be argued that follow up for longer than the three months chosen in this study is necessary before organic disease can be safely excluded. The time interval chosen, however, was sufficient for all the appropriate investigations to be undertaken in order that the presence or absence of organic disease could be established. Previous studies have shown that when a diagnosis of the irritable bowel syndrome is made after appropriate investigation, the subsequent discovery of organic disease occurs in fewer than $5 \%$ of patients. ${ }^{14}$

The use of a structured psychiatric assessment interview established current psychiatric 'caseness' in $33 \%$ of the 64 patients interviewed all but one of whom had a functional gastrointestinal disorder. Previous or current psychiatric 'caseness' was found in $54 \%$ of patients with functional disorders compared with $12.5 \%$ of patients with organic disorders, a prevalence similar to that previously recorded in the irritable bowel syndrome. ${ }^{15}{ }^{16}$ Anxiety provoking life situations were found in $30 \%$ of the 64 patients studied. Although this proportion was similar in the functional and organic groups, the numbers are small and caution is in order; nonetheless, it is reasonable to conclude that the association of functional disorders with psychiatric 'caseness' is greater than it is with anxiety provoking situations.

Studies using life event inventories in irritable bowel patients have similarly failed to show any significant difference from control groups. ${ }^{178}$ In a study of 101 patients with the irritable bowel syndrome, however, stressful life events were reported by $50 \%$ of patients during 12 months of follow up of whom three quarters experienced an exacerbation of alimentary symptoms at the time of the life event. ${ }^{19}$ In another study, psychiatric symptoms and life events were assessed using the Bedford College methodology in patients who had recently had an appendicectomy. ${ }^{20}$ The findings are of relevance to the irritable bowel syndrome; $32 \%$ of patients whose appendix was not acutely inflamed experienced psychiatric symptoms compared with $16 \%$ of patients with acute appendicitis. Though the proportion of patients experiencing severe life events before appendicectomy was similar in the two groups, the type of life events experienced by patients whose appendix was normal closely resembled those found in patients with depression. Continuing abdominal pain in the year after appendicectomy was experienced in $58 \%$ of patients in whom a normal appendix had been removed compared with $24 \%$ whose appendix had been acutely inflamed. ${ }^{20}$

Stressful life situations in gastrointestinal clinical referrals have been studied in the year preceding the onset of abdominal pain using the Bedford College methodology. ${ }^{21}$ Significant differences between patients with organic and functional disorders were found in the frequency of stressful events and difficulties occurring in the 38 week period before referral. No evidence of organic disease was found in $59 \%$ of 135 patients studied, of whom $67 \%$ had experienced a severe event or major difficulty compared with $23 \%$ of those with an organic disease and $23 \%$ of a community comparison group. The majority of severe events in the functional group involved loss 
and disappointment and were comparable with those events known to produce depression. ${ }^{10}$ Though no psychiatric data were reported, the occurrence of severe events and difficulties was significantly associated with the onset of psychiatric disorders in the study group (Craig: personal communication).

In our study, life situations alone did not appear to be associated with functional gastrointestinal disorders unless they provoked an anxiety disorder. A psychiatric illness episode and/or an anxiety provoking life situation preceded the onset of bowel symptoms in two-thirds and one-third respectively of the 48 patients with a functional disorder compared with none of the 16 with organic disease. There remains a third of patients with functional disorders in whom there is neither a stressful life situation nor an overt psychiatric disorder. Though in such patients a different causal mechanism may exist, the possibility remains that previous undisclosed psychosocial and behavioural factors may still be important.

Our findings are consistent with the hypothesis that the irritable bowel is a behavioural disorder in which the physiological responses to stress are expressed as somatic symptoms, the principal determinants of which are likely to include previous illness experience and illness behaviour. ${ }^{22}$ Irritable bowel patients are more likely to have multiple somatic complaints and to consult a physician for minor illnesses compared with the general population. ${ }^{2324}$ Symptoms of somatised anxiety, however, have been shown to be as prevalent in irritable bowel patients as in those experiencing similar bowel symptoms but who do not report them. ${ }^{25}$ Whether or not the patients seek medical advice therefore appears to be more influenced by psychosocial factors than by the severity of the associated somatic distress. ${ }^{25}$

Such a background to functional gastrointestinal disorders accounts for the difficulties experienced in their management. Anxiety disorders render irritable bowel patients more refractory to conventional therapy and may engender anxiety in the clinician thereby encouraging continued investigation further increasing the patients' anxiety. Inappropriate concentration on possible somatic factors to the exclusion of psychological and social aspects can adversely affect both the doctor-patient relationship and the outcome. ${ }^{26}$

Nonetheless exclusion of organic disease and the definition of a firm clinical diagnosis cannot be achieved without a careful history, examination and necessary investigation. The clinician should assess for each patient the influence of the three major contributory elements namely somatic factors, psychiatric factors, and life situations. Thereafter, the cornerstone of management remains that of a sympathetic discussion of these factors together with firm reassurance. We would suggest that patients can best be helped to acquire a different perspective and a better understanding of their disabling symptoms when to soma and psyche is added circumstance. ${ }^{27}$

We wish to thank Drs W Sircus and A Ferguson for their permission to study patients under their care. We are particularly indebted to Mrs Maura Walker, Mrs Wendy Carrington and Mrs Sarah Raikes who undertook the domiciliary interviews, Miss Cecilia MacIntyre of the Medical Computing and Statistics Centre for her invaluable help with the statistical analysis of data and Mrs Molly Brown for her secretarial assistance.

\section{References}

1 Harvey RF, Salih SY, Read AE. Organic and functional disorders in $\mathbf{2 0 0 0}$ gastroenterology out-patients. Lancet 1983; 1: 632-4.

2 Thompson WG, Heaton KW. Functional bowel disorders in apparently healthy people. Gastroenterology 1980; 79: $283-8$.

3 Ingham J, Miller PMcC. Consulting with mild symptoms in general practice. Soc Psychiatry 1982; 17: 77-88.

4 Ingham J, Miller PMcC. Self-referral: social and demographic determinants of consulting behaviour. $J$ Psychom Res 1983; 27: 233-42.

5 Horrocks JC, De Dombal FT. Clinical presentation of patients with dyspepsia: detailed symptomatic study of 360 patients. Gut 1978; 19: 19-26.

6 Manning AP, Thompson WG, Heaton KW, Morris AF. Towards positive diagnosis of the irritable bowel. $\mathrm{Br}$ Med J 1978; 2: 653-4.

7 Surtees PG, Dean C, Ingham JG, Kreitman NB, Miller $\mathrm{PMcC}$, Sashidharan SP. Psychiatric disorder in women from an Edinburgh community: association with demographic factors. Br J Psychiatry 1983; 142: 238-46.

8 Dean C, Surtees PG, Sashidharan SP. Comparison of research diagnostic systems in an Edinburgh community sample. Br J Psychiatry 1983; 142: 247-56.

9 Miller PMcC, Ingham JG. Dimensions of experience. Psychol Med 1983; 13: 471-29.

10 Finlay-Jones RA, Brown GW. Types of stressful life events and the onset of anxiety and depressive disorders. Psychol Med 1981; 11: 803-15.

11 Miller PMcC, Ingham JG. Dimensions of experience and symptomatology. J Psychosom Res 1985; 29: 475-88.

12 Fielding JF. A year in out-patients with the irritable bowel syndrome. Irish J Med Sci 1977; 146: 162-6.

13 Ferguson A, Sircus W, Eastwood MA. Frequency of 'functional' gastrointestinal disorders. Lancet 1977; 2: 613-4.

14 Holmes KM, Salter RH. Irritable bowel syndrome-a safe diagnosis. Br Med J 1982; 285: 1533-4.

15 Young SJ, Alpers DH, Norland CC, Woodruff RA. Psychiatric illness and the irritable bowel syndrome. Practical implications for the primary physician. Gastroenterology 1976; 70: 162-6. 
16 Gomez J, Dally P. Psychologically mediated abdominal pain in surgical and medical out-patient clinics. $\mathrm{Br}$ Med J 1977; 1: 1451-3.

17 Fava, GA, Pavan L. Large bowel disorders. I. Illness configuration and life events. Psychother Psychosom 1976; 27: 93-9.

18 Mendeloff AI, Monk M, Siegel CI, Lilienfield A. Illness experience and life stresses in patients with irritable colon and with ulcerative colitis. $N$ Engl J Med 1970; 282: 14-7.

19 Svedlund J. Psychotherapy in irritable bowel syndrome. A controlled outcome study. Acta Psychiatr Scand 1983; 67: suppl. 306: 1-86.

20 Creed F. Life events and appendicectomy. Lancet 1981; 1: 1381-5.

21 Craig TKJ, Brown GW. Goal frustration and life events in the aetiology of painful gastrointestinal disorder. J Psychosom Res 1984; 28: 411-21.

22 Latimer PR. Irritable bowel syndrome: a behavioural model. Behav Res Ther 1981; 19: 475-83.

23 Whitehead WE, Winget C, Fedoravicius AS, Wooley S, Blackwell B. Learned illness behaviour in patients with irritable bowel syndrome and peptic ulcer. Dig Dis Sci 1982; $27: 202-8$.

24 Sandler RS, Drossman DA, Nathan HP, McKee DC. Symptom complaints and health care seeking behaviour in subjects with bowel dysfunction. Gastroenterology 1984; 87: 314-8.

25 Welch GW, Hillman LC, Pomare EW. Psychoneurotic symptomatology in the irritable bowel syndrome: a study of reporters and non-reporters. Br Med J 1985; 291:1382-4.

26 Kreitman N, Sainsbury R, Pearce K, Costain WR. Hypochondriasis and depression in out-patients in a general hospital. Br J Psychiatry 1965; 111: 607-15.

27 Ford MJ, Eastwood J, Eastwood MA. The irritable bowel syndrome: soma and psyche. Psychol Med 1982; 12: 705-7. 